\title{
Variação temporal e espacial das características limnológicas de um ecossistema lótico no Cerrado do Mato Grosso
}

\author{
Monica Elisa Bleich ${ }^{1 *}$ \\ Carlos José da Silva ${ }^{1}$ \\ Amintas Nazareth Rossete ${ }^{2}$ \\ Universidade do Estado de Mato Grosso - UNEMAT \\ ${ }^{1}$ Campus Universitário de Alta Floresta \\ ${ }^{2}$ Campus Universitário de Nova Xavantina \\ Caixa Postal 324, CEP 78580-000, Alta Floresta - MT, Brasil \\ *Autor para correspondência \\ mebleich@yahoo.com.br
}

Submetido em 20/05/2008

Aceito para publicação em 19/11/2008

\section{Resumo}

O objetivo deste estudo foi caracterizar um córrego na área de Cerrado do Mato Grosso sob aspectos limnológicos durante um ciclo anual e verificar sua relação com o regime hidrológico e alterações antrópicas do sistema terrestre adjacente. Foram selecionados para a realização das coletas dois pontos na área do Parque do Bacaba e dois em área com grande influência antrópica, principalmente atividade pecuária. A coleta de dados foi realizada bimestralmente, no sentido nascente-foz, de setembro de 2001 a agosto de 2002. Verificou-se nas estações de amostragem a temperatura da água, profundidade, transparência da água, oxigênio dissolvido, $\mathrm{pH}$, condutividade elétrica, material em suspensão e vazão total. Foram mais evidentes as variações espaciais do que as variações temporais. Ao longo do ano, os valores da transparência, material em suspensão, condutividade elétrica e oxigênio dissolvido apresentaram as maiores variações. No período se seca foram registradas as menores concentrações de oxigênio dissolvido. Entre as estações de amostragem apenas o pH não apresentou diferença significativa, as demais variáveis diferiram significativamente entre pelo menos duas estações de amostragem. Entre o período de seca e o chuvoso apenas a profundidade da coluna d'água e a vazão total diferiram significativamente.

Unitermos: ecossistema lótico, limnologia, Cerrado, qualidade da água

\section{Abstract}

Temporal and spatial variation of the limnological characteristics of a lotic ecosystem in the Cerrado of Mato Grosso. This study aimed to characterize a stream in the area of Cerrado of Mato Grosso according to limnological characteristics during an annual cycle and to assess its relationship with the hydrological regime and anthropogenic changes of the adjacent land system. Two collection points in the stream were selected which passed through the Parque do Bacaba in addition to two other in areas of anthropogenic influence, mainly cattleraising activity. Data collection was performed bimonthly in downstream order, from September 2001 to August 2002. At the sampling sites, the water temperature, depth, water transparency, dissolved oxygen, $\mathrm{pH}$, electric conductivity, suspended material and total stream discharge were verified. The spatial variations were more 
obvious than the temporal changes. The values of water transparency, suspended material, electric conductivity and dissolved oxygen showed the greatest variations. The lowest concentrations of dissolved oxygen in the stream were recorded in the dry period. Among the sampling sites, only the $\mathrm{pH}$ did not present any significant differences, and the other variables differed significantly between at least two sampling sites. Between the dry and rainy periods, only the depth of the water column and total stream discharge differed significantly.

Key words: lotic ecossistem, limnology, Cerrado, water quality

\section{Introdução}

Ao longo dos séculos os ambientes aquáticos vêm sofrendo com a ação antrópica desordenada, e os organismos nem sempre são capazes de resistir ou desenvolver estratégias que permitam superar as condições perturbadoras.

Os biomas brasileiros são alvo de constantes agressões. O Bioma Cerrado nos últimos anos foi submetido a transformações radicais devido ao avanço da agricultura e pecuária. Extensas áreas são desmatadas, sem reservas de amostra dos ecossistemas naturais que possam funcionar como banco genético e refúgio da fauna e da flora (Novaes Pinto, 1993). A intensa atividade humana que degrada o Cerrado também degrada os corpos d'água inseridos nesse Bioma, principalmente aqueles de pequeno porte, cujos volumes d'água, em muitos casos, são insuficientes para promover a auto depuração, em função das grandes quantidades de resíduos que recebem (Rocha, 1993).

A ausência de vegetação nas margens destes ambientes aquáticos permite que todo material lixiviado pelo escoamento superficial atinja estes ambientes, concentrando substâncias tóxicas e nutrientes, que pode os eutrofizar a ponto de se tornarem inviáveis à vida (Esteves, 1998). Primavesi et al. (2003) mostram em seu estudo o efeito negativo da interferência antrópica na qualidade da água de uma microbacia hidrográfica.

Os pequenos cursos d'água em regiões de Cerrado que ainda não perderam suas condições naturais, de uma maneira geral, apresentam-se cobertos por uma densa mata de galeria que dificulta a entrada de raios solares, o que reduz a produtividade primária, tendo em vista a ausência de plantas aquáticas flutuantes ou submersas (Rocha, 1993).

As matas de galeria funcionam como corredores ecológicos da flora e da fauna, são importantes na manutenção da estabilidade térmica da água, fornecem energia ao sistema nas folhas, frutos e sementes que caem nos cursos d'água, contribuem para a redução dos processos erosivos das margens e do conseqüente assoreamento do leito do curso d'água. Em áreas com atividades agropecuárias têm importância fundamental na manutenção da qualidade da água (Fonseca et al., 2001).

Os efeitos de degradação atingem grande amplitude, que afetam diretamente as atividades econômicas e prejudicam de forma indireta diferentes segmentos da sociedade, uma vez que a água é o recurso natural mais utilizado e de maior importância para a vida no planeta (Smith e Petrere Jr., 2000).

A interferência antrópica nos sistemas naturais freqüentemente tem fragmentado os hábitats aquáticos, comprometendo o funcionamento de todo o sistema. A destruição da vegetação ripária e de extensas áreas no entorno dos ecossistemas aquáticos pode levar a alterações no seu funcionamento, principalmente nas condições físicas, como profundidade e concentração de material em suspensão, e conseqüentemente afetar outras condições limnológicas. O objetivo deste estudo foi caracterizar um córrego na área de Cerrado do Estado de Mato Grosso sob aspectos limnológicos ao longo de um ciclo anual e verificar sua relação com o regime hidrológico e alterações antrópicas do sistema terrestre adjacente.

\section{Material e Métodos}

\section{Caracterização da área de estudo}

O córrego estudado, denominado Córrego Bacaba, situa-se na região sudeste do Estado de Mato Grosso entre as coordenadas geográficas $14^{\circ} 36^{\prime}-52^{\circ} 22^{\prime} \mathrm{S}$ e $14^{\circ} 44^{\prime}$ - $52^{\circ} 17^{\prime} \mathrm{W}$, no município de Nova Xavantina (Figura 1). O Córrego Bacaba pertence à Bacia Hidrográfica do Tocantins, e é um Córrego de $2^{\mathrm{a}}$ ordem de acordo com a classificação de Strahler (Gordon et al., 1995). 


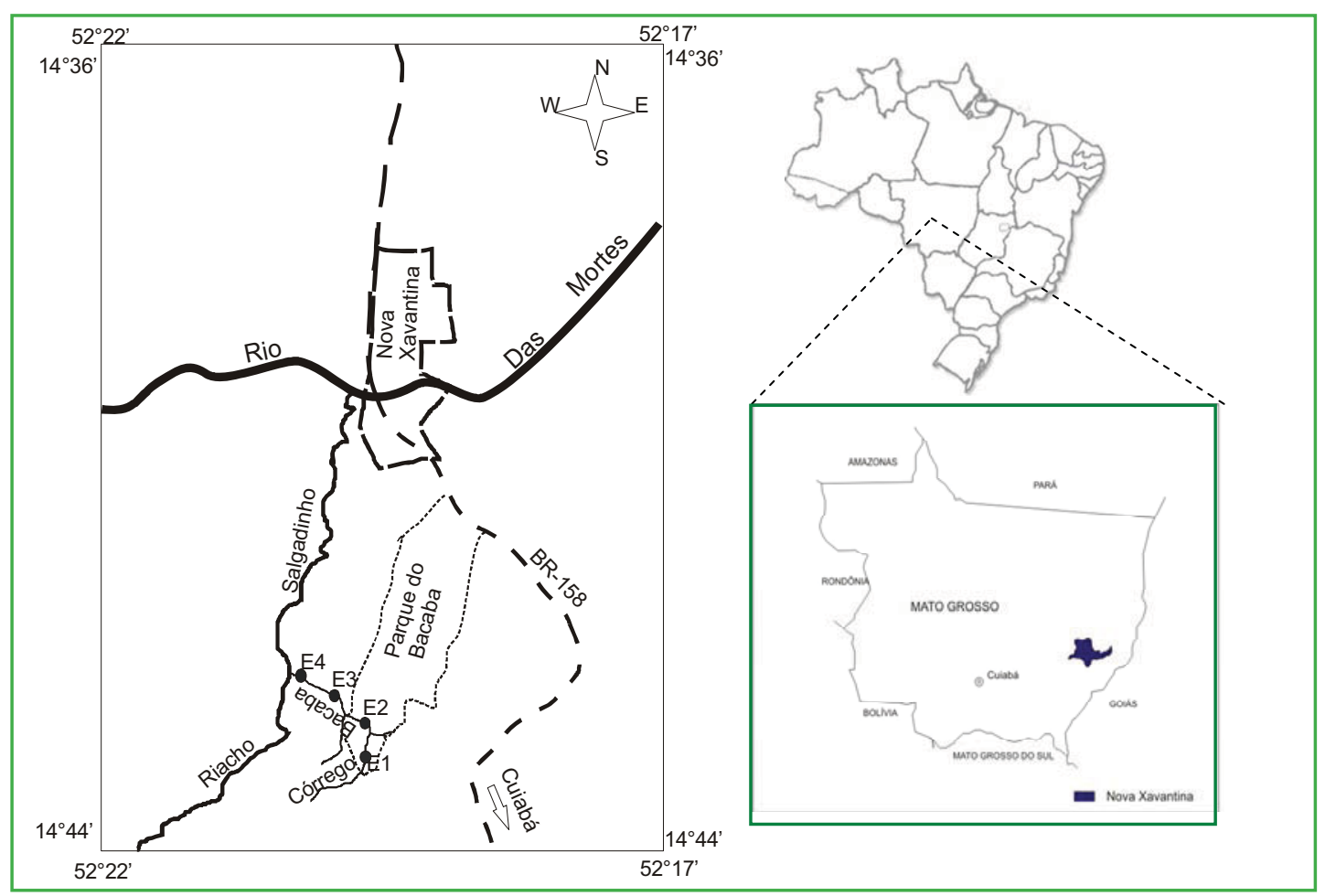

FIGURA 1: Localização da área de estudo em Nova Xavantina, MT.

O clima da região é do tipo Aw segundo a classificação de Köppen (Vianello e Alves, 2000), predominantemente do tipo tropical com duas estações bem definidas, sendo um período seco e um período chuvoso.

A precipitação média anual nos últimos treze anos é de $1.536 \mathrm{~mm}$, com médias de temperaturas em torno de $25,5^{\circ} \mathrm{C}$, sendo julho o mês mais frio e setembro o mais quente, segundo dados da estação meteorológica do Parque do Bacaba.

O Córrego possui $5 \mathrm{~km}$ de extensão, nasce próximo ao limite sul do Parque Municipal "Parque do Bacaba", com área de 497ha. Ao atravessar o Parque, o córrego percorre uma área de relevo variado, desde locais mais íngremes com afloramentos rochosos de quartzito e filito onde se formam cachoeiras, até áreas de relevo mais plano onde ocorrem enchentes sazonais formando brejos. Ao sair da área do Parque, na região sudoeste, o córrego Bacaba percorre propriedades particulares antropizadas onde predomina a atividade pecuária e a mata de galeria foi destruída, e deságua no Riacho Salgadinho que é afluente do Rio das Mortes. A largura média do córrego é de $1 \mathrm{~m}$, atingindo $3 \mathrm{~m}$ nas porções represadas, e a profundidade não ultrapassa $80 \mathrm{~cm}$.

$\mathrm{Na}$ área do Parque do Bacaba a vegetação ripária encontra-se conservada, mas na área externa do Parque a vegetação se estende por apenas um ou dois metros, ou inexiste em alguns trechos, sendo substituída por pastagens como acontece em toda a área de entorno. $\mathrm{Na}$ porção do córrego externa a área do Parque o fluxo de água se apresenta muito reduzido nos meses de agosto a outubro (período de seca), cessando-se e então se formam pequenos reservatórios que servem de bebedouro para bovinos.

Além da grande destruição da cobertura vegetal nas áreas externas ao Parque para atividade pecuária, queimadas são freqüentes e destroem não apenas a cobertura vegetal existente nesta área, mas também adentram o Parque do Bacaba e comprometem as espécies ali presentes.

Na porção do córrego externa a área do Parque o fluxo de água se apresenta muito reduzido nos meses de agosto a outubro (período de seca), cessando-se e 
então se formam pequenos reservatórios que servem de bebedouro para bovinos.

\section{Amostragem}

Foram selecionados quatro pontos ao longo da extensão do córrego, buscando amostrar as diferentes condições encontradas no Córrego. Dentre os locais, foram selecionados dois na área do Parque do Bacaba $\mathrm{e}$ dois em áreas antropizadas. As estações de amostragem são identificadas como Estação 1 (E1), Estação 2 (E2), Estação 3 (E3) e Estação 4 (E4). AE1 localiza-se próximo a nascente do córrego e a E2 na área do Parque, porém nesta porção foi construída uma pequena barragem para captação de água com a finalidade de abastecimento público de um bairro do município.

A coleta de dados foi realizada bimestralmente, no período matutino, no sentido nascente-foz, ao longo de um ano, de setembro de 2001 a agosto de 2002.

Para a caracterização limnológica do córrego foram determinadas as variáveis temperatura da água, transparência da água, concentração de oxigênio dissolvido, $\mathrm{pH}$, contutividade elétrica, material em suspensão, profundidade e vazão total.

A temperatura da água foi determinada por meio de termômetro de mercúrio. A transparência da água foi determinada a partir da leitura visual do disco de Secchi. A concentração de oxigênio dissolvido foi determinada pelo método de Winkler. As amostras de água para a determinação do oxigênio dissolvido foram coletadas com garrafa de Van Dorn. O pH e a condutividade elétrica foram determinados por meio de medidor portátil Jenco Eletronics, modelo 6350, com eletrodos específicos. O material em suspensão foi quantificado pelo método de gravimetria por filtração a vácuo, segundo as técnicas de Teixeira et al. (1965). Para a filtragem da água foram utilizados filtros AP-20 Milipore. A profundidade foi determinada por meio de régua graduada. A vazão foi determinada em um ponto próximo a desembocadura do córrego Bacaba no riacho Salgadinho, através de valores da velocidade medida por meio de um correntômetro, em seções transversais da área do córrego, conforme a metodologia proposta por Pinto e Holtz (1995).

Dados de precipitação pluviométrica $(\mathrm{mm})$ e temperatura média mensal $\left({ }^{\circ} \mathrm{C}\right)$, medidos de setembro de 2001 a agosto de 2002, foram coletados na Estação Meteorológica de Nova Xavantina (Ministério da Agricultura, $9^{\circ}$ Distrito de Meteorologia) localizada no Campus Universitário de Nova Xavantina, junto ao Parque do Bacaba.

\section{Análise dos dados}

Os dados foram submetidos a um Teste t para verificação de possível variação espacial e temporal entre as estações de amostragem. As medidas de tendência central (Média) e de variabilidade ou dispersão (Desvio Padrão e Coeficiente de Variação) foram determinadas para as variáveis, considerando dados espaciais e temporais. Considerou-se pequena variabilidade quando o coeficiente de variação foi até $10 \%$; média variação se acima de $10 \%$ até $20 \%$; e grande variação se maior que 20\% (Fonseca e Martins, 1996).

\section{Resultados e Discussão}

\section{Comportamento meteorológico e hidrológico}

As maiores precipitações pluviométricas mensais no período de estudo ocorreram de outubro a fevereiro, período chuvoso, totalizando $1370 \mathrm{~mm}$, e as menores precipitações foram registradas entre março e setembro, período de seca, com um total de $73 \mathrm{~mm}$. A maior média mensal da temperatura ambiente foi $26,6^{\circ} \mathrm{C}$, no mês de setembro, enquanto que a menor foi de $21,5^{\circ} \mathrm{C}$, no mês de junho (Figura 2).

A profundidade da coluna d'água das estações de amostragem variou de zero a $80 \mathrm{~cm}$, não havendo diferença significativa entre as estações da área do Parque e as externas a ele (Figura 3).

A vazão média registrada no córrego Bacaba foi 1851/s, sendo registrada a maior vazão em março (3001/s) e a menor em setembro de 2001 e julho de 2002 (Figura 4), quando o córrego não apresentava fluxo de água na foz. Com exceção da porção do córrego na área do Parque onde havia fluxo de água, o curso do córrego manteve água apenas em represas isoladas. 


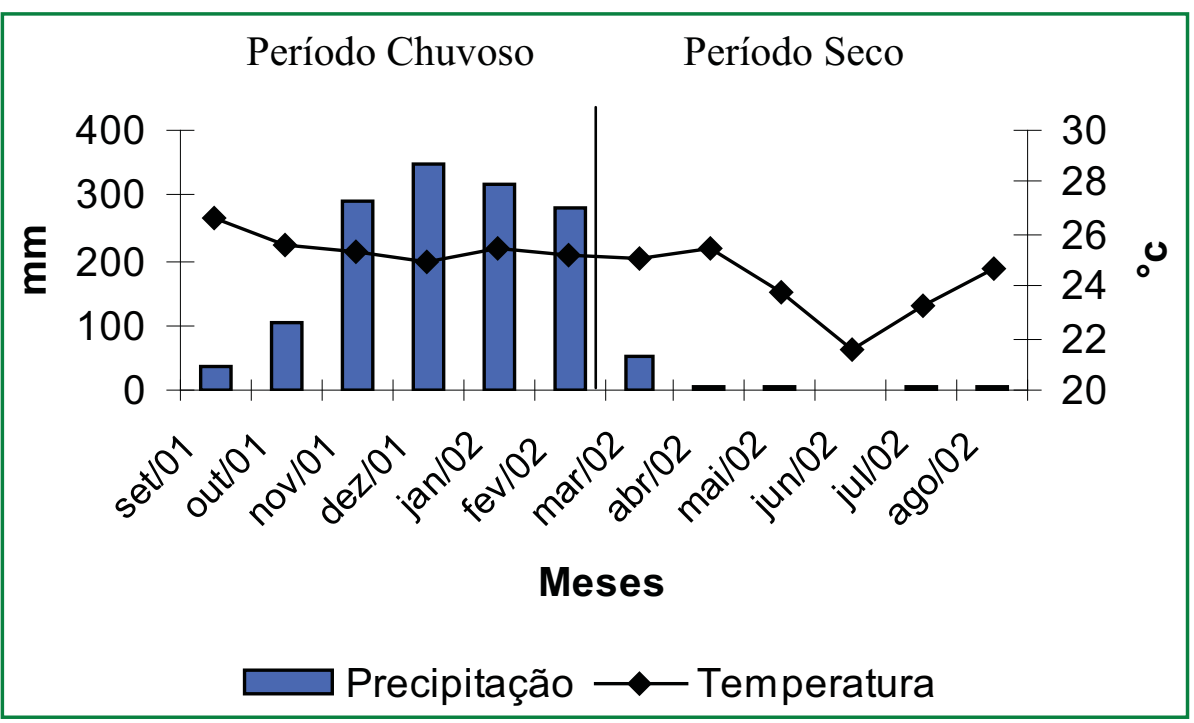

FIGURA 2: Dados climáticos registrados no período de setembro/2001 a agosto/2002 em Nova Xavantina, MT.

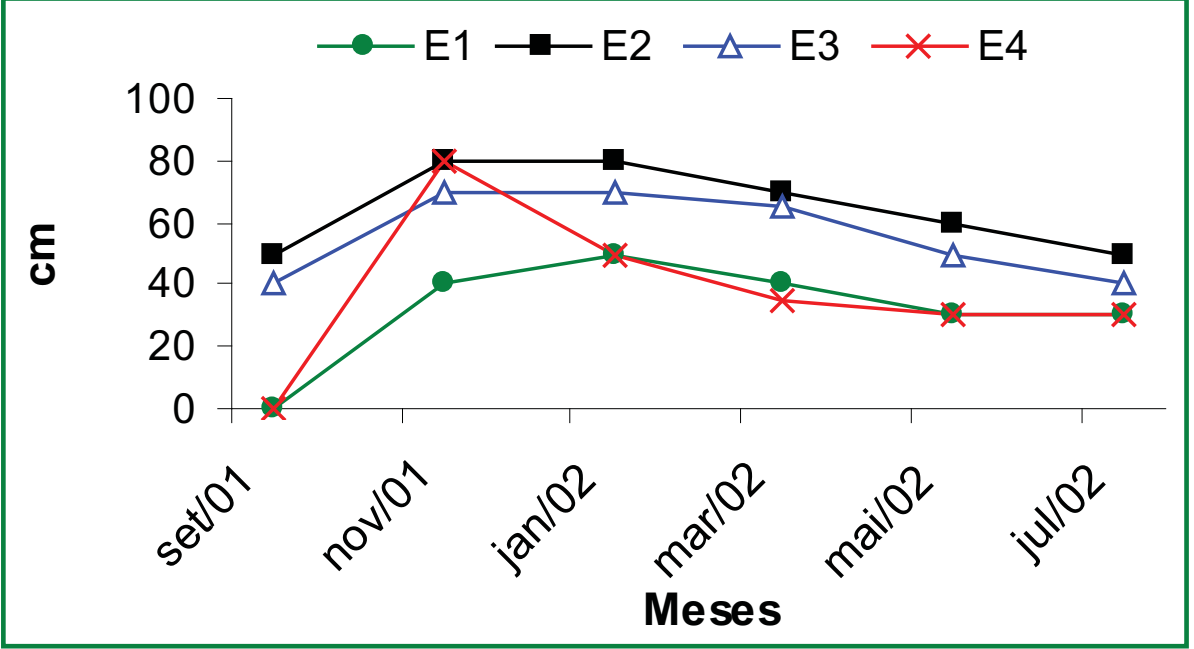

FIGURA 3: Variação da profundidade da coluna d'água no córrego Bacaba.

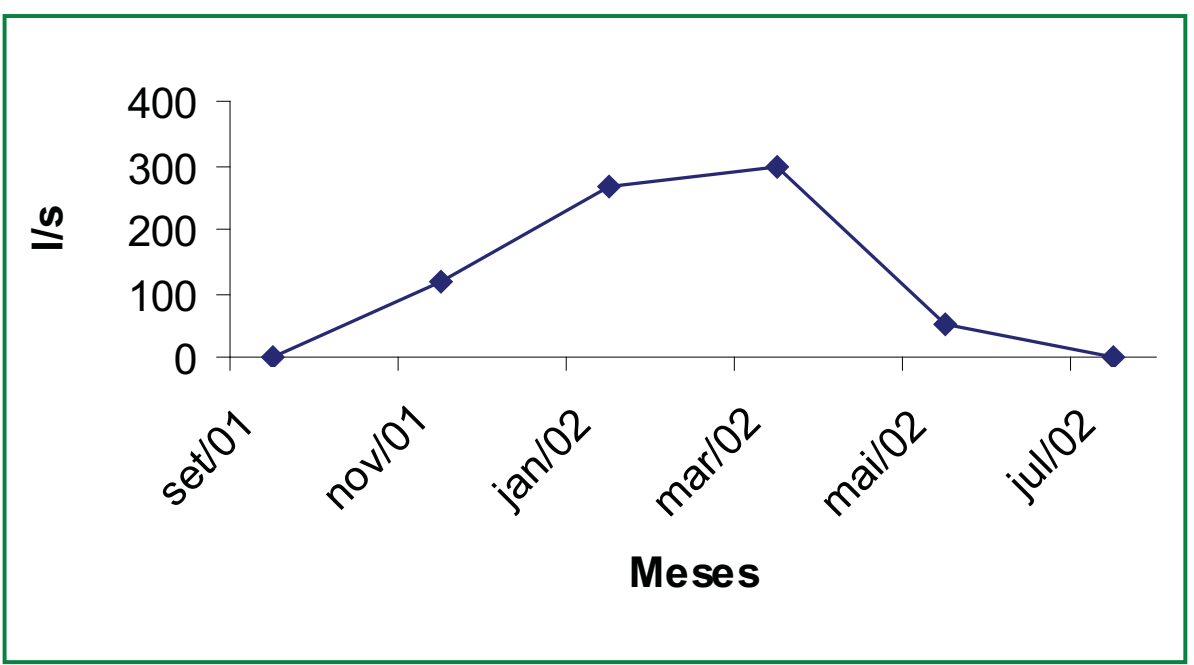

FIGURA 4: Vazão do córrego Bacaba em Nova Xavantina-MT. 


\section{Condições limnológicas}

A Figura 5 mostra a variação das condições físicas e químicas nas estações de amostragem no Córrego Bacaba ao longo do ciclo anual.

A sazonalidade foi evidente em todo o curso do córrego e para todas as variáveis analisadas, sendo que durante o período chuvoso foram registradas condições limnológicas mais homogêneas do que na seca.

A temperatura da água variou de $21^{\circ} \mathrm{C}$ a $26^{\circ} \mathrm{C}$, sendo as maiores registradas na E2 (reservatório no Parque) exceto em novembro, início do período chuvoso, e março - início do período de seca onde foi registrada a menor temperatura entre os pontos amostrados. A variação entre as estações de amostragem está possivelmente relacionada com a cobertura vegetal que permite maior ou menor exposição aos raios solares. A barragem construída na E2 contribui para a retenção de um volume maior de água ao longo do ano, e aliada a vegetação conservada, pode estar contribuindo para que a temperatura mantenha-se relativamente constante e maior do que nas demais porções do córrego na maior parte do ciclo anual.

Segundo Margalef (1983), a flutuação da temperatura das águas correntes é relativamente ampla quando em córregos com pequena profundidade e a turbulência tende a destruir gradientes. Maier (1978) ressalta que as condições específicas dos ambientes lóticos resultam de variações de velocidade, volume e fonte de suprimento de água, profundidade, tipo de substrato e sombreamento, como também de fatores que atuam sazonalmente, diariamente e mesmo em um dado momento ao longo do curso do rio.

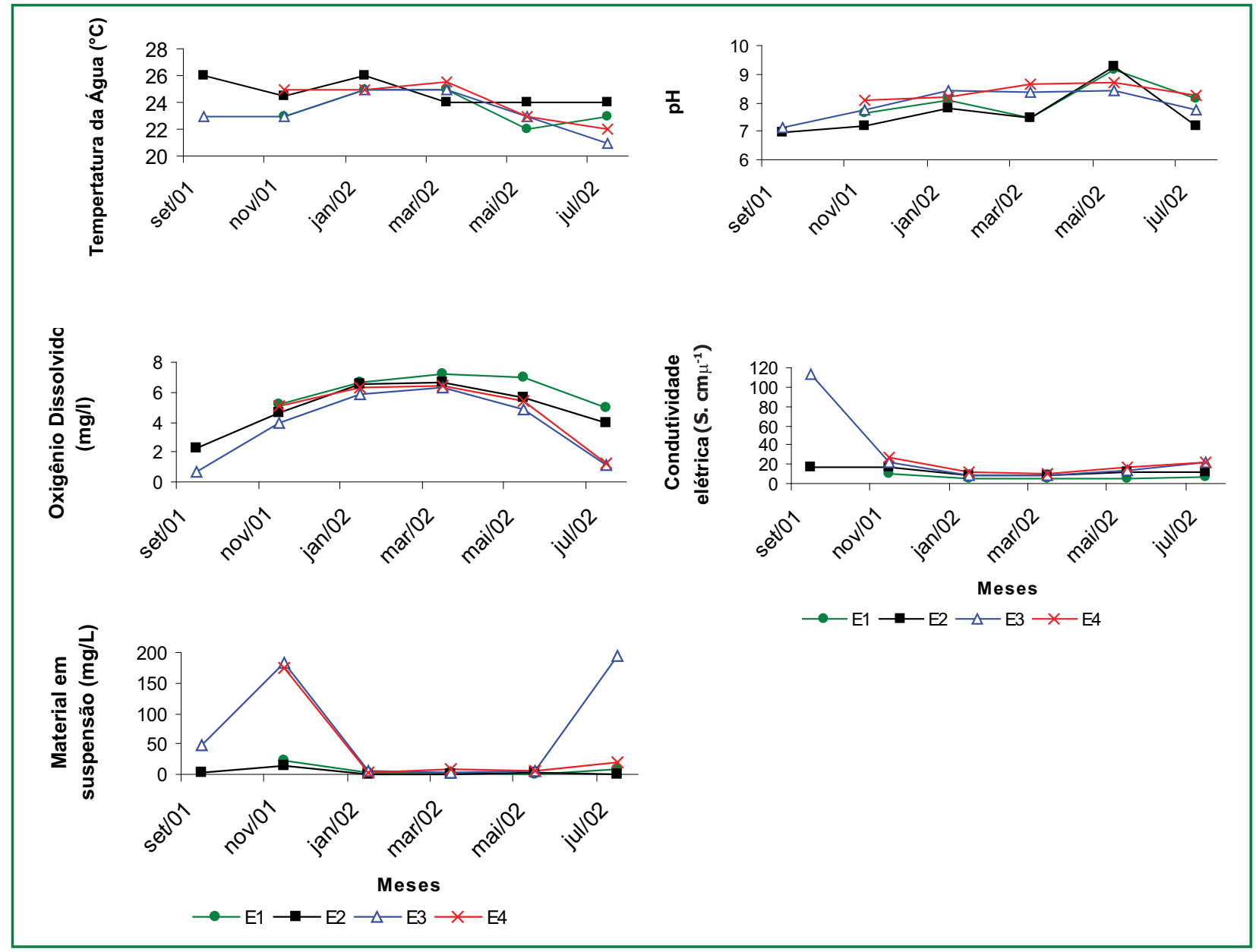

FIGURA 5: Características limnológicas do Córrego Bacaba no período de setembro de 2001 a julho de 2002. 
A transparência da água variou de total a águas com baixa transparência no final do período de seca e início das chuvas (Tabela 1).

As maiores concentrações de material em suspensão foram registradas nos pontos localizados na área antropizada (E3 e E4). A maior quantidade de material em suspensão no córrego esteve relacionada com o início das chuvas onde houve um aumento do material em suspensão em todo o curso d'água, principalmente na área antropizada. No período de seca, houve redução da concentração de material em suspensão enquanto o córrego apresentava fluxo de água normal, porém, quando na área externa ao Parque o córrego passou a funcionar com reservatórios isolados foi registrado um aumento de material em suspensão, principalmente onde bovinos adentram no córrego.

TABELA 1: Transparência da água do córrego Bacaba em Nova Xavantina-MT.

\begin{tabular}{lcccc}
\hline Amostragem & E1 & E2 & E3 & E4 \\
\hline Set/01 & $*$ & Total & 10 & $*$ \\
Nov/01 & 28 & 32 & 8,5 & 8 \\
Jan/02 & Total & Total & Total & Total \\
Mar/02 & Total & Total & Total & Total \\
Mai/02 & Total & Total & Total & Total \\
Jul/02 & Total & Total & Total & Total \\
\hline
\end{tabular}

*Ausência de água

Valores mais elevados de material em suspensão no período de cheia também foram encontrados por Henry e Curi (1983) no rio Pardo. De acordo com Souza e Rocha (1996), atividades pecuárias sem técnicas de manejo adequadas contribuem para a exportação de sedimentos pelos rios durante a estação chuvosa.

A causa dos valores mais elevados de material em suspensão nas estações de amostragem na área antropizada possivelmente está relacionada com a baixa densidade de cobertura vegetal do solo causada pela ação antrópica, seja pela atividade pecuária ou pelo fogo. Em agosto, queimadas são freqüentes, e no período deste estudo o fogo devastou a vegetação do entorno, inclusive grande parte da vegetação do Parque.
O fogo ao remover a vegetação gera um aumento no escoamento superficial das águas pluviais, diminuindo a infiltração de água no solo, aumentando o carreamento de partículas e tornando-o mais susceptível aos processos erosivos (Silva et al., 2001).

Além do aumento da concentração de material em suspensão que contribui para a redução da transparência da água, a retirada da vegetação está causando o assoreamento do córrego que recebe sedimentos das áreas expostas no entorno. Baccaro (1999) registra em seu estudo que a intensidade das chuvas foram determinantes no volume do escoamento pluvial e na quantidade de material em suspensão.

A maioria dos nutrientes, sedimentos e matéria orgânica que afluem para um córrego são provenientes dos distúrbios ambientais causados pela ocupação humana na bacia (Pinto e Cavalcanti, 2001). Na região central do planalto central brasileiro é muito grande a variação da vazão entre a estação chuvosa e o período de estiagem (Salgado et al., 2001), assim os sistemas aquáticos sofrem grandes modificações nas condições limnológicas em função do mau uso do ambiente de entorno, muitas prejudiciais aos organismos aquáticos.

A concentração de oxigênio dissolvido afeta drasticamente a diversidade de vida aquática. As maiores concentrações de oxigênio dissolvido no córrego foram registradas no período chuvoso. No período de seca a concentração de oxigênio dissolvido oscilou de águas bem oxigenadas (E1) a concentrações limitantes à vida aquática (E3). A boa oxigenação da água se manteve para a E1 e E2 no período chuvoso, para a E3 e E4 a concentração de oxigênio aumentou um pouco, mas não atingiu aquelas registradas para a porção do córrego na área do Parque. Valores mais elevados na área do Parque (E1 e E2) no período de seca, podem ser explicados pela manutenção do fluxo de água nesta porção do córrego proporcionado pela presença de vegetação ripária.

Valores mais elevados de oxigênio dissolvido na água no período chuvoso também foram observados por Iocca (2000), no córrego Sangradouro em Cáceres, Mato Grosso, e por Smith e Petrere Jr. (2000), no rio Pirapora em São Paulo. Souza e Rocha (1996) encontraram neste período as menores concentrações de oxigênio dissolvido na água do rio Areias em Goiás. 
De acordo com a teoria do contínuo fluvial os valores de oxigênio dissolvido tendem a diminuir em direção a foz (Vannote et al., 1980). No córrego Bacaba houve uma redução dos valores em direção a foz durante o ciclo anual, porém descontínua. Essa descontinuidade pode estar relacionada com a interrupção do fluxo de água na porção do córrego exterior a área do Parque que faz com que o ambiente passe a funcionar como sistemas lênticos. Essa mudança de dinâmica pode ser a responsável pelas grandes variações nas concentrações de oxigênio dissolvido, aliado a presença freqüente de animais adentrando as águas paradas.

A redução da transparência da água na $\mathrm{E} 3$ e sua coloração esverdeada durante a estiagem, associada à redução da concentração de oxigênio dissolvido, possivelmente estão indicando enriquecimento de compostos orgânicos neste período.

A baixa concentração de oxigênio dissolvido na água é conseqüência do desequilíbrio entre a entrada e a decomposição da matéria orgânica no ambiente (Fagundes e Shimizu, 1997) e a concentração de matéria orgânica aliada às altas temperaturas das regiões tropicais contribui decisivamente para o grau de desoxigenação da água no período de seca (Esteves, 1998).

O oxigênio é relativamente escasso e muitas vezes extremamente variável na água e, logo, é muitas vezes um fator limitante em águas com uma carga pesada de matéria orgânica para os organismos aquáticos especialmente para os animais (Odum, 1988). Segundo Sperling (1998), para a manutenção da vida aquática aeróbia, são necessários teores mínimos de oxigênio dissolvido de 2 a $5 \mathrm{mg} / \mathrm{l}$, de acordo com o grau de exigência de cada organismo.

De acordo com Zagatto et al. (1999), para manter a sobrevivência e a reprodução dos organismos a água precisa apresentar concentrações de oxigênio dissolvido superiores a $5 \mathrm{mg} / \mathrm{l}$ e pH entre 6 e 9. Se a água apresentar valores de oxigênio dissolvido entre 3 e $5 \mathrm{mg} / 1$ e pH entre 5 e 6 ou entre 9 e 9,5 os organismos sobreviverão, porém a reprodução pode ser afetada. Valores de oxigênio dissolvido na água inferiores a $3 \mathrm{mg} / 1$ podem comprometer a sobrevivência dos organismos, bem como $\mathrm{pH}$ inferior a 5 ou superior a 9,5.
As águas do córrego apresentaram-se levemente alcalinas ao longo do estudo. Durante o período de seca, os E1 e E4 apresentaram valores médios de $\mathrm{pH}$ semelhantes, bem como os E2 e E3. A grande maioria dos corpos d'água continentais tem $\mathrm{pH}$ variando entre 6 e 8, no entanto, pode-se encontrar ambientes ácidos ou mais alcalinos (Esteves, 1998). Os valores de $\mathrm{pH}$ registrados no córrego Bacaba permitem a sobrevivência dos organismos aquáticos, ao contrário, a concentração de oxigênio dissolvido apresentou-se limitante na porção do córrego externa ao Parque no período de seca.

Zillmer et al. (2007) detectaram no estudo realizado no Ribeirão Salgadinho, do qual o Córrego Bacada é afluente, valores de $\mathrm{pH}$ mais elevados no período de seca e também registraram elevadas concentrações de $\mathrm{Ca}$ e $\mathrm{Mg}$ nas rochas da bacia de drenagem, os quais em contato com a água se transformam em carbonatos de cálcio e magnésio e tendem a elevar o $\mathrm{pH}$ da água. Os autores atribuem à ação das chuvas e conseqüente aumento o volume de água do Ribeirão para reduzir a concentração dos elementos que contribuem para a elevação do $\mathrm{pH}$.

A condutividade elétrica da água apresentou baixos valores ao longo do ano, sendo registrados os menores valores no período chuvoso. Os menores valores foram registrados na área do Parque. Na E1 foi registrada a menor média anual e esta foi crescente em direção a foz (E4).

No período chuvoso, devido à entrada de material alóctone, incluindo íons, deveria haver aumento da condutividade elétrica, porém a maior entrada de água resultou numa diminuição das concentrações de íons e, conseqüentemente, na condutividade elétrica, caracterizando um efeito de diluição (Pompêo et al., 1997; Moschini-Carlos et al., 1999).

Baixa condutividade também foi observada no córrego Fundo, no município de Barra do GarçasMT por Melo (1995). Segundo esse autor, este fator associado à alta transparência da água em todo o período da seca indica uma baixa produtividade primária para este local. Necchi Jr. et al. (2000) registraram na Serra da Canastra baixos valores de condutividade, mas registraram elevados valores de nutrientes inorgânicos, 
como nitrato, ortofosfato, potássio e ferro, e de DQO. Os autores inferem que a maior parte dos íons esteja combinado com substâncias orgânicas, formando complexos orgânicos em solução e assim não detectadas pela condutividade.

Zillmer et al. (2007) registraram no Ribeirão Salgadinho valores mais elevados de condutividade elétrica que os registrados no córrego Bacaba, principalmente no final do período seco e incío das chuvas.

Segundo Esteves (1998), a condutividade elétrica da água pode fornecer importantes informações tanto sobre o metabolismo do ecossistema aquático como sobre fenômenos importantes que ocorrem na sua bacia de drenagem. $\mathrm{O}$ aumento dos valores demonstra o aporte de materiais e deterioração da qualidade da água. Segundo Smith et al., (1997), a condutividade é indicadora de poluição orgânica.

Os resultados do Teste $t$ mostram diferença significativa entre as estações de amostragem situados interna e externamente ao Parque do Bacaba apenas para as variáveis material em suspensão $(\mathrm{p}=0,025) \mathrm{e}$ oxigênio dissolvido $(\mathrm{p}=0,023)$.

Entre as estações de amostragem foi registrada diferença significativa entre a profundidade das E1 e E2 $(p=0,0002), E 1$ e E3 $(p=0,0010), E 2$ e E4 ( $p=0,0049)$ e E3 e E4 ( $=0,0239)$, entre a temperatura da água e a transparência da água das E2 e E3 ( $p=0,0341$ e p = 0,0480 respectivamente). A condutividade elétrica da água apresentou diferença significativa entre E1 e E2 ( $p=$ $0,0024), E 1$ e E3 ( $p=0,0132), E 1$ e E4 ( $p=0,0043), E 2$ e E4 ( $p=0,0098), E 3$ e E4 $(p=0,0111)$. A concentração de oxigênio dissolvido diferiu significativamente entre E1 e E2 $(p=0,0122)$, E1 e E3 $(p=0,0173)$, E2 e E3 $(p=0,0147)$, E3 e E4 $(p=0,0422)$ e o material em suspensão entre E1 e E2 ( $p=0,0405)$. Para as demais estações de amostragem e variáveis não foi registrada diferença significativa. Entre as variáveis avaliadas, foi registrada diferença significativa entre o período de seca e chuvoso apenas para a profundidade da coluna d'água nas E2 $(p=0,009), E 3(p=0,006)$ e E4 $(0,028)$ e para a vazão total $(p=0,050)$.

Os níveis de variabilidade das variáveis limnológicas nas estações de amostragem ao longo do ano foram diferenciados. Na E1 a temperatura da água e o pH apresentaram uma pequena variação, a temperatura ambiente e o oxigênio dissolvido uma média variação e uma grande variação foi apresentada pela transparência, condutividade e material em suspensão. Na E2 uma pequena variação foi registrada para a temperatura da água, uma média variação para a temperatura ambiente e pH e uma grande variação para a transparência, condutividade, oxigênio dissolvido e material em suspensão. Na E3 e na E4 a temperatura da água, do ar e o pH apresentaram uma pequena variação enquanto que a transparência, a condutividade, o oxigênio dissolvido e o material em suspensão apresentaram grande variação. A vazão também apresentou uma grande variação anual.

Carvalho et al. (2000) atribuem o aumento das concentrações de material em suspensão ao efeito da intensificação de atividades agrícolas e pecuárias que consequentemente contribuem para o carreamento da camada superficial do solo para o ambiente aquático, e este ao se decompor consome o oxigênio dissolvido.

Donadio et al. (2005) concluíram que a presença de remanescentes de vegetação ciliar auxilia na proteção dos recursos hídricos, e as características do solo e seus diferentes usos influenciam na qualidade da água das microbacias, sendo esta melhor nas nascentes com vegetação natural remanescente do que nas nascentes com uso agrícola.

As chuvas e os períodos de estiagem são interferências naturais que alteram a estrutura e o funcionamento dos sistemas aquáticos, ao contrário, as influências de origem antrópica, também alteram a dinâmica, porém muitas vezes não temporariamente $\mathrm{e}$ ocasionam o comprometimento do funcionamento do ambiente.

As grandes variações espaciais nas variáveis analisadas indicam que o ambiente aquático é sensível às modificações no ambiente de entorno, aumentando as concentrações de material em suspensão na porção do córrego onde a vegetação foi retirada para a implantação da atividade pecuária, e reduzindo o oxigênio dissolvido.

As condições do entorno dos pontos amostrados possivelmente são os responsáveis pelas variações 
espaciais registradas. As atividades antrópicas que envolvem queimadas, remoção da mata de galeria e ausência de manejo adequado da pecuária são responsáveis pela deterioração da qualidade da água do córrego Bacaba, principalmente pela grande redução da concentração de oxigênio dissolvido e da transparência da água, além de fragmentar o fluxo d'água no período de seca.

As chuvas têm papel importante para a autodepuração de ambientes aquáticos de pequeno porte como o córrego Bacaba, mas ela só não é suficiente para a manutenção da integridade desses sistemas. São necessárias medidas de proteção para que não sejam excluídos do Bioma Cerrado, e assim a alimentação dos grandes rios e a biodiversidade aquática não sejam comprometidas.

\section{Referências}

Baccaro, C. A. D. 1999. Processos erosivos no domínio cerrado. In: Guerra, A. J. T.; Silva, A. S. \& Botelho, R. G. M. (Eds). Erosão e conservação dos solos: Conceitos, temas e aplicações. Bertrand Brasil, Rio de Janeiro, Brasil, p.195-227.

Carvalho, A. R.; Schlittler, F. H. M.; Tornisielo, V. L. 2000. Relações da atividade agropecuária com parâmetros físicos químicos da água. Química Nova, 23 (5): 618-622.

Donadio, N. M. M.; Galbiatti, J. A.; De Paula, R. C. 2005. Qualidade da água de nascentes com diferentes usos do solo na Bacia Hidrográfica do Córrego Rico, São Paulo, Brasil. Engenharia Agrícola, 25 (1): 115-125.

Esteves, F. A. 1998. Fundamentos da Limnologia. Interciência/ FINEP, Rio de Janeiro, Brasil, 602pp.

Fagundes, R. C.; Shimizu, G. Y. 1997. Avaliação da qualidade da água do Rio Sorocaba-SP, através da comunidade bentônica. Revista Brasileira de Ecologia, 1: 63-66.

Fonseca, J. S.; Martins, G. A. 1996. Curso de Estatística. $6^{\text {a }}$ ed. Atlas, São Paulo, Brasil, 320pp.

Fonseca, C. E.; Ribeiro, J. F.; Souza, C. C.; Rezende, R. P.; Balbino, V. K. 2001. Recuperação da vegetação de matas de galeria: estudos de caso no Disttrito Federal e entorno. In: Ribeiro, J. F.; Fonseca, C. E. \& Sousa-Filho, J. C. (Eds). Cerrado: Caracterização e recuperação de matas de galeria. Embrapa Cerrados, Planaltina, Brasil, p.815-870.

Gordon, N. D.; MacMahon, T. A.; Finlayson, B. L.; Gippel, C. J.; Nathan, R. J. 1995. Stream hydrology: an introduction for ecologists. John Wiley Professio, New York, USA, 444pp.

Henry, R.; Curi, P. R. 1993. Estudos ecológicos na represa do rio Pardo (Botucatu, SP, Brasil), a distribuição horizontal e variação anual do material em suspensão. Revista Brasileira de Biologia, 43 (4): 311-316.
Iocca, F. A. S. 2000. Caracterização limnológica do córrego Sangradouro nas épocas de seca e de chuva - Cáceres/MT. Dissertação de Mestrado, Universidade de Brasília, Brasil, 83pp.

Maier, M. H. 1978. Considerações sobre características limnológicas de ambientes lóticos. Boletim do Instituto de Pesca, 5 (2): 75-90.

Margalef, R. 1983. Limnología. Omega, Barcelona, Espanha, 1009pp.

Melo, C. E. 1995. Hábitos alimentares, diversidade de peixes e condições limnológicas de um córrego de cerrado, Barra do Garças - MT. Dissertação de Mestrado, Universidade Federal de Mato Grosso, Brasil, 180pp.

Moschini-Carlos, V.; Pompêo, M. L. M.; Henry, R. 1999. Dinâmica da comunidade perifítica na zona de desembocadura do rio Paranapanema, represa do Jurumirim, SP. In: Henry, R. (Ed.). Ecologia de reservatórios: Estrutura, função e aspectos sociais. FUNDIBIO/FAESP, Botucatu, Brasil, p.690-734.

Necchi Jr., O.; Branco, L. H. Z.; Branco, C. C. Z. 2000. Características limnológicas da bacia do Alto Rio São Franscisco, Parque Nacional da Serra da Canastra, Minas Gerais. Acta Limnologica Brasiliensia, 12 (1): 11-22.

Novaes Pinto, M. 1993. Cerrado: Caracterização, ocupação e perspectivas. $2^{\mathrm{a}}$ ed. UnB, Brasília, Brasil, 432pp.

Odum, E. P. 1988. Ecologia. Guanabara Koogan, Rio de Janeiro, Brasil, 434pp.

Pinto, M. A. T.; Cavalcanti, C. G. B. 2001. Uso e ocupação do solo e a qualidade das águas. In: Fonseca, F. O. (Ed.). Olhares sobre o Lago Paranoá. Secretaria do Meio Ambiente e dos Recursos Hídricos, Brasília, Brasil, p.264-271.

Pinto, N. L. S.; Holtz, A. C. T. 1995. Medições de vazão. In: Pinto, N. L. S.; Holts, A. C. T.; Martins, J. A. \& Comide, F. L. S. (Eds). Hidrologia Básica. Edgard Blücher, São Paulo, Brasil, p.182-204.

Pompêo, M. L. M.; Henry, R.; Moschini-Carlos, V.; Padovani, C. R. 1997. A influência da macrófita aquática Echinochloa polystachya (H.B.K.) Hitchcok nas condições físicas e químicas da água na zona de desembocadura do rio Paranapanema na represa de Jurumirim SP. Revista Brasileira de Ecologia, 1 (2): 44-53.

Primavesi, O.; Freitas, A. R.; Primavesi, A. C.; Oliveira, H. T. 2003. Water quality of the Conchim's creek watershed in São Carlos, SP, Brasil, occupied by Beef and Dairy Cattele Activities. Brazilian Archives of Biology and Technology, 45 (2): 209-217.

Rocha, A. J. A. 1993. Caracterização limnológica do Distrito Federal. In: Novaes Pinto, M. (ed.). Cerrado: Caracterização, ocupação e perspectivas. $2^{\mathrm{a}}$ ed. UnB, Brasília, Brasil, p.469-492.

Salgado, G. S. M.; Chiarini, H.; Braga Neto, P.; Moretti, W. 2001. Geração de energia. In: Fonseca, F. O. (Ed.). Olhares sobre o Lago Paranoá. Secretaria do Meio Ambiente e dos Recursos Hídricos, Brasília, Brasil, p.191-197.

Silva, J. C.; Fiedler, N. C.; Silva Jr., M. C.; Ribeiro, G. A.; Felfili, J. M. 2001. Diagnóstico das principais causas de incêndios florestais em unidades de conservação do distrito federal. Anais do Workshop Sobre Incêndios Florestais no Cerrado, 1: 35-41.

Smith, W. S.; Barrella, W.; Cetra, M. 1997. Comunidade de peixes como indicadora de poluição ambiental. Revista Brasileira de Ecologia, 1: 67-71. 
Smith, W. S.; Petrere Jr., M. 2000. Caracterização limnológica da bacia de drenagem do Rio Sorocaba, São Paulo, Brasil. Acta Limnologica Brasiliensia, 12 (2): 15-27.

Souza, M. J. M.; Rocha, A. J. A. 1996. Areias river (Goiás, Brasil) Assessment to the water with view to use in supplying the Federal District. Anais do Simpósio Sobre o Cerrado, 8: 223-225.

Sperling, E. V. 1998. Qualidade da água em atividades de mineração. In: Dias, L. E. \& Mello, J. W. V. (Eds). Recuperação de áreas degradadas. Sociedade Brasileira de Áreas Degradadas, Viçosa, Brasil, p.95-105.

Teixeira, J. G.; Tundisi, J. G.; Kutner, M. B. 1965. Plankton studies in mangrove: The standing stock and some ecological factors. Boletim do Instituto de Oceanografia, 24: 23-41.
Vannote, R. L.; Minshall, G. W.; Cummins, K. W.; Sedell, J. R.; Cushing, C. E. 1980. The river continuum concept. Canadian Journal of Fisheries and Aquatic Science, 37: 130-137.

Vianello, R. L.; Alves, A. R. 2000. Meteorologia básica e aplicações. UFV, Viçosa, Brasil, 449pp.

Zagatto, P. A.; Lorenzetti, M. L.; Lamparelli, M. C.; Salvador, M. E. P.; Menegon Jr., N.; Bertoletti, E. 1999. Aperfeiçoamento de um índice de qualidade de águas. Acta Limnologica Brasiliensia, 11 (2): 111-126.

Zillmer, T. A.; Varella, R. F.; Rossete, A. N. 2007. Avaliação de algumas características físico-químicas da água do Ribeirão Salgadinho-MT. Holos Environmental, 7 (2): 123-138. 